\title{
Logistical Implications of Animal Welfare Concepts in Beef Exports
}

\author{
Nicolás Castro \\ Universidad Nacional del Sur \\ Raúl Oscar Dichiara \\ IIESS (CONICET-Universidad Nacional del Sur)
}

\begin{abstract}
The commercial success of the food industry is largely dependent on the viability of various aspects in the logistical chain. In regard to RVG (Rational Voisin Grazing), bovine production is very efficient and economical because it is based on grasses which mitigates greenhouse effects. Bovine production also aims to achieve a final organic product which makes it possible to obtain differential market prices; additionally, it recognizes and addresses issues regarding Animal Welfare $(A W)$. The treatment of animals under this grazing system must be continued in all aspects of the logistic chain to avoid production losses in regard to both quality and quantity. It is estimated that the losses caused by ineffective application of $A W$ in the logistics chain and wasteful efforts in $R V G$, are enough to feed half a million people. The players in the beef chain must guarantee transparency and traceability of information in the entire chain so as to assess new market demands and requirements. Customers demand quality and inoculated products and require maximum guarantees so as not to jeopardize their health. Recent SENASA's [1] regulations points to the restructuring of the entire value chain, orienting it towards the new reality of external markets and making it stricter in regards to health, quality, and food safety.
\end{abstract}

Keywords: Animal Welfare, Export logistics Chain, Organic Meat, RVG, Argentina

\section{INTRODUCTION}

The food industry is quite complex and interlinked such that the actions of each player have a significant impact on the final product. Hence, more coordination efforts are required to ensure the production of quality and safe products. This paper reviews the role of logistics (in regard to the concept of Animal Welfare) in optimizing the three sectors in the added value chain of beef processing: these sectors are production, freezing, and trading.

Efficient livestock practices must be observed in each aspect of the value chain so as to obtain products of good quality and quantity. It is important to note that such practices have low implementation cost, and are substantially beneficial for producers, carriers, manufacturers, and consumers. The entry into new markets is only possible if the production process caters for the consumer's requirements by addressing the following questions: What is the consumer looking for? What product features attracts the consumer? What could motivate him/her to consume Argentine organic meat? The final business outcomes will then depend on the capability of the production system and other supply chain players to 
provide healthy products using sustainable resources and promoting Animal Welfare. This concept, which is part of the agenda of countries interested in exporting beef to the European Union, is one of the means of differentiation available to Argentine producers.

Alterations in health and control aspects, in both public and private sectors, enabled the transition from reactive control systems to quality assurance systems. It has also enabled the incorporation of private certifiers in the accreditation of certain intangible properties of differentiated products (such as organic products). These changes have influenced the development and expansion of a differentiated market with high purchasing power, which seeks to incorporate reliable information on all its attributes in regards to meat products.

\section{MEAT PRODUCTION}

One condition for the production of quality organic meat is appropriate feeding system of the animals, which is clearly defined by the Rational Voisin Grazing (RVG):

1. R: This system is referred to as rational because of the following reasons:

a) The main aspect of this technique is the ability of humans to think critically, identify concepts, question them, and find coherence or contradiction between them. This results in generation of thoughts and ideas that are different from those we already have.

b) The utilization of grass is made using rations (precise and appropriate proportions). As a summary: Rational $=$ Reasoning + Rationing.

2. V: The RVG technique was named in honor of Prof. Dr. André Marcel Voisin, who was a French Biochemist and farmer. He died in 1964.

3. G: Grazing is defined as the encounter between the animal and the grass, which is consumed daily to boost the vital nutrients of the animals.

4. RVG: This is the art of managing pastures used to feed cattle and other animals (such as buffaloes, goats, sheep and horses) which enables the farmer to obtain the best results in terms of production and efficiency in resource allocation. RVG also protects the environment and promotes its recovery, as well as respecting the four universal laws on which it is based.

Considering these insights, RVG is superior to conventional livestock management systems because of the following aspects:

- Increased productivity: small paddocks with high animal load and specific management enables farmers to utilize up to $90 \%$ of the available fodder. The harvest in extensive livestock hardly rises by $30 \%$; therefore, it is possible to obtain a greater daily bovine weight gain compared to the conventional system. Productivity, which is measured per hectare under the RVG management, can be at least 25,000 liters of milk or 1,000 kilograms of meat per year (depending on the animal load that have been maintained).

- Reduction of average costs: the non-utilization of plows, chemical fertilizers, herbicides and the diminished use of antibiotics, allow the application of natural solutions. This ensures that the introduction of improved species is made on the natural vegetal tapestry. Such practices allow the reduction of the required feed (concentrated) in milk production to $15 \%$ or $20 \%$ daily. Additionally, the greater the animal load in grazing (which is possible only with RVG) the larger the production of milk and meat. This results in decreased fixed costs of the final product and increased profits.

- Increased soil fertility: Land fertility when using RVG is always increasing despite the nonutilization of chemical fertilizers. This is mainly because RVG uses organic matter such as feces, urine, and other organic materials from the ecosystem to improve soil fertility. The mineralization and the humification of organic waste, which are carried out by bacteria, fungi, worms, beetles, and other living organisms that inhabit the soil, also play a very important role in improving land fertility 
- Environmental protection: RVG promotes high rates of carbon dioxide emissions and mitigates soil erosion. Grazing allows improved carbon sequestration, both by soil organic matter and by appropriate photosynthesis of grasslands. Therefore, this technology is considered as an important axis of obtaining neutral balances and positive carbon balances. The environment is an essential aspect in the meat production industry. Extensive research indicates [2] that grazing under the RVG technology ensures proper management of pasture. As an illustration, a single hectare under RVG management yields annual carbon dioxide emissions of approximately 365 cows.

- Positive energy balance: All the energy used in the production of meat in regards to pasture is generated from the sun and human efforts with the exception of anti parasites, vaccines, and machines for forage production.

- Production of clean food: RVG accommodates and adheres to the norms and regulations set by particular countries to ensure and guarantee production of quality and safe meat products. This gives RVG products a competitive advantage as compared to other products.

- Acknowledgment of Animal Welfare (AW): Under RVG systems, animals are treated with dignity and respect. The greatest possible comfort is offered to the animals by providing them with abundant food and water for consumption. RVG creates a scenario where livestock do not struggle to meet their daily needs of food and water. Additionally, this system ensures that the animals are not subjected to any form of cruelty and their living conditions are up to standards. The animals are handled carefully and gently. The OIE [3] animal welfare standards are not health measures but play an important role in international trade; this is because they are the only scientific-based standards of global application which are accepted by the nations engaged in the international trade.

- Increased real economic gain: Under RVG, the method of land use produces a greater real benefit because the unit costs are lower and even. If organic foods are sold at higher prices, the profits are higher which results in more profitable livestock. Additionally, there is protection and improvement of basic capital such as the soil and other natural resources.

\section{THE SLAUGHTERHOUSES}

Animal Welfare (AW) practices during transportation and export are vital because they affect the animals' productivity potential. Besides the ethical aspect of AW, it is an important economic practice meant to avoid economic losses caused by animal injuries and diseases. AW also improves the quality of the final product, thus increasing the profitability of the product along the chain.

Different stakeholders in the livestock value chain provide most of the animal's physical needs (such as food, water, and shelter) and also avoid potential risks such as illnesses or injuries. Animal welfare encompasses three of the following five freedoms: a) freedom from hunger and thirst; b) comfort and c) freedom from pain, injuries, and illnesses. However, many problems arise due to ignorance or negligence which arise due to the absence of the other two freedoms: d) freedom to manifest natural behavior and e) freedom from fear and distress (FAWC, 1992) [4]. Undoubtedly, one of the obstacles to applying these concepts is aggressive actions towards animals and to a great extent, ignorance by animal handlers.

Animal welfare should be perceived as an effective tool of increasing the productivity of a farm and enhancing the effectiveness of relocation and slaughtering processes. Adhering to AW guidelines can help in identifying and amending errors in the production system, transport equipment and farm infrastructure. Due to the complexity of the practices and approaches in the livestock value chain, which have significant impacts on the quality and quantity of the final products, this paper highlights the implications of transportation of livestock to slaughterhouses on the quality of the final products. 


\section{Transportation to the Slaughterhouse}

Transportation to the slaughterhouse involves a moving "corral livestock" in a very unstable environment that tests the resilience and adaptation mechanisms of the animals. This link has multiple stress factors because they are associated with a series of unpredictable and risky activities to the lives of the cattle. In addition to unfavorable environmental factors (such as heat, cold, and humidity), a social regroup system for the new individuals is also a crucial factor. This is because most of the players in the meat production value chain are only engaged for a short period of time. Additionally, there are several responsibilities which are shared simultaneously between the producers, transporters, slaughterers, slaughterhouses, veterinarians and State agencies that regulates and oversees various practices and transportation means of livestock.

The questions below can help us to understand the importance of transport in the meat supply chain:

a) What is the lifespan (in hours) of a single beef cattle?

Answer: Mature Steer/heifer: 2.5 years x 8,670 hours. $=21,675$ hours.

b) How much time is spent from when a steer is loaded until it is slaughtered?

Answer: Approximately 24 hours, which represents $0.11 \%$ of the spent time. Although it seems as little time, it depends on the quality of meat obtained.

$$
\frac{T T}{L E}=\frac{24 S t d}{8,670 S t d / J h r \times 2.5 J h r}=\frac{24}{21,675}=0.011,
$$

where: $\mathrm{TT}=$ Traffic Time,

$\mathrm{LE}=$ Life Expectancy.

\section{On-site Inspection}

Inspection of live animals before slaughter is an essential step in the production of quality meat which is safe for human consumption. Pre-slaughter inspection is important because abnormalities in posture, movement, and behavior can only be detected in a living animal. Ante-mortem inspection can improve the efficiency of the production operation by identifying animals that are unfit for human consumption.

Such inspection must be carried out on arrival at the slaughterhouse. Sufficient light, either artificial or natural, is needed so as to observe animals during motion and rest. Equally important, one must also consider the conditions of the transport vehicle and if any animal has suffered damages during transportation.

Another factor to take into account at the time of slaughter is desensitization of the animal to achieve the right degree of immobilization. This facilitates the slashing of the blood vessels such that the bleeding is adequate whilst avoiding anxiety, pain, anguish or suffering by the animal [5]. Humanitarian sacrifice regulations require that the duration of unconsciousness induced by a stunning method should be clearly longer than the sum of the time interval between the end of stunning, the killing and the time it takes for blood loss to cause death.

Although all players and stakeholders in the logistic chain are concerned about the course of the production export process, beef farmers and consumers are the ones facing the greatest economic consequences. This deduction is based on the following facts:

- Livestock damage: it is estimated that the loss in bovine animals amounts to approximately USD 37,849,127, which is equivalent to the annual consumption of beef for approximately 300,000 people in a country.

- Poor meat quality: the loss due to poor meat quality is estimated to be USD 30,244,284, which is equivalent to the consumption of approximately 290,000 beef cattle in the country.

Therefore, the total losses could feed around 582,406 people a year. In order to avoid such losses, regulations, resolutions and rules of conduct should be implemented and observed such as those issued by SENASA. 


\section{Price Difference Between Organic and Common Cuts}

The premium price paid in foreign markets for organic meat products is significant, and the large supermarket chains in these markets constantly enlarge the space for organic products. In Spain, the price difference between organic cuts and common supermarkets is $19 \%$.

\section{INTERNATIONAL MARKETING}

The logistic processes for the exportation of organic meat includes all operations from the establishment of the production facility to the point of destination abroad. This process involves various stages and steps which engages several parties such as transporters, dispatchers, freight agents, and inspectors, among others, who must coordinate and cooperate to achieve the ultimate objectives. These processes involved in the exportation of meat are under a door-to-door operation (DTD), although the majority of export contracts for beef and its by-products are made under FOB (Free On Board) purchase clauses or FOT (Free On Track). The logistics inherently involved in the exportation process include:

- Ground transportation of animals: This process is done within the country of origin and is regulated by SENASA (Argentine Health Cattle National Service).

- Exportation and processing: This process is generally carried out within the same production line and within the same space as the work directed to the domestic market, with the exception of rituals such as the kosher work. The associated antemortem and post-mortem controls are carried out within the plant and under the auspices of the chief inspector of the authorized sanitary service and of the certifier.

- Packaging and labeling: This process is carried out in the cold storage of the processing plant. The labels differ according to the variety of the products. In the case of half a bovine animal, a stamp is applied. For cuts and by-products, the label adheres to the wet product. Depending on the requirements at the destination, a mandatory high-impact color label and an optional label with detailed and distinguishing data are used. The information contained in the labels must be in the official language of the destination country. According to the international standards of traceability, the food label and the bar code are the main tools that allows effective traceability. The food label should specifically show data defining the origin of the meat product. Additionally, the label may also indicate where the animal was fattened. Stakeholders in beef chains involved in the exportation of organic meat must ensure transparent and clear information throughout the meat value chain from birth to final packaging for presentation to the consumer. This demonstrates compliance with all requirements of organic production. All packaged boxes must carry a mandatory label. 
FIGURE 1

LOGISTIC SEQUENCE OF THE ORGANIC BEEF EXPORT

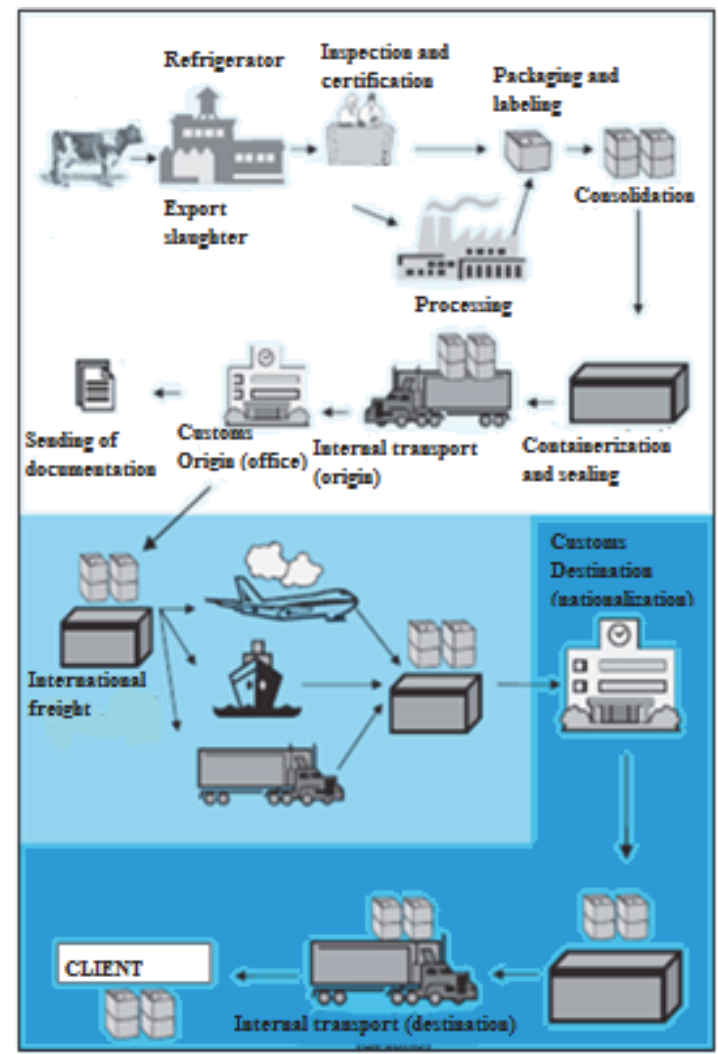

Source: IPCVA[6]

- Consolidation: This process involves the grouping of boxes containing the product to be exported. The load rests on the container floor, a practice known as "floor loaded." The consolidated merchandise is loaded in containers, which are sealed with a plastic device.

- Containment: The container $(8 \times 8 \times 20$ feet or $8 \times 8 \times 40$ feet $)$ is easily transferable using various modes of transport, which eliminates individualizing the load and the cost of rehandling small units at the intermodal transfer point. Additionally, it favors the "door-todoor" mode when being transported by truck. The temperature of the cargo must be controlled to maintain the viability of all fresh or frozen products (excluding canned goods) which are perishable products. For frozen cargo, a temperature of $-18^{\circ} \mathrm{C}$ (maximum limit $10 /-9^{\circ} \mathrm{C}$ ) and for chilled cuts of $0^{\circ} \mathrm{C}$ should be applied. 
FIGURE 2

CONTAINERS AND CARGO WEIGHTS

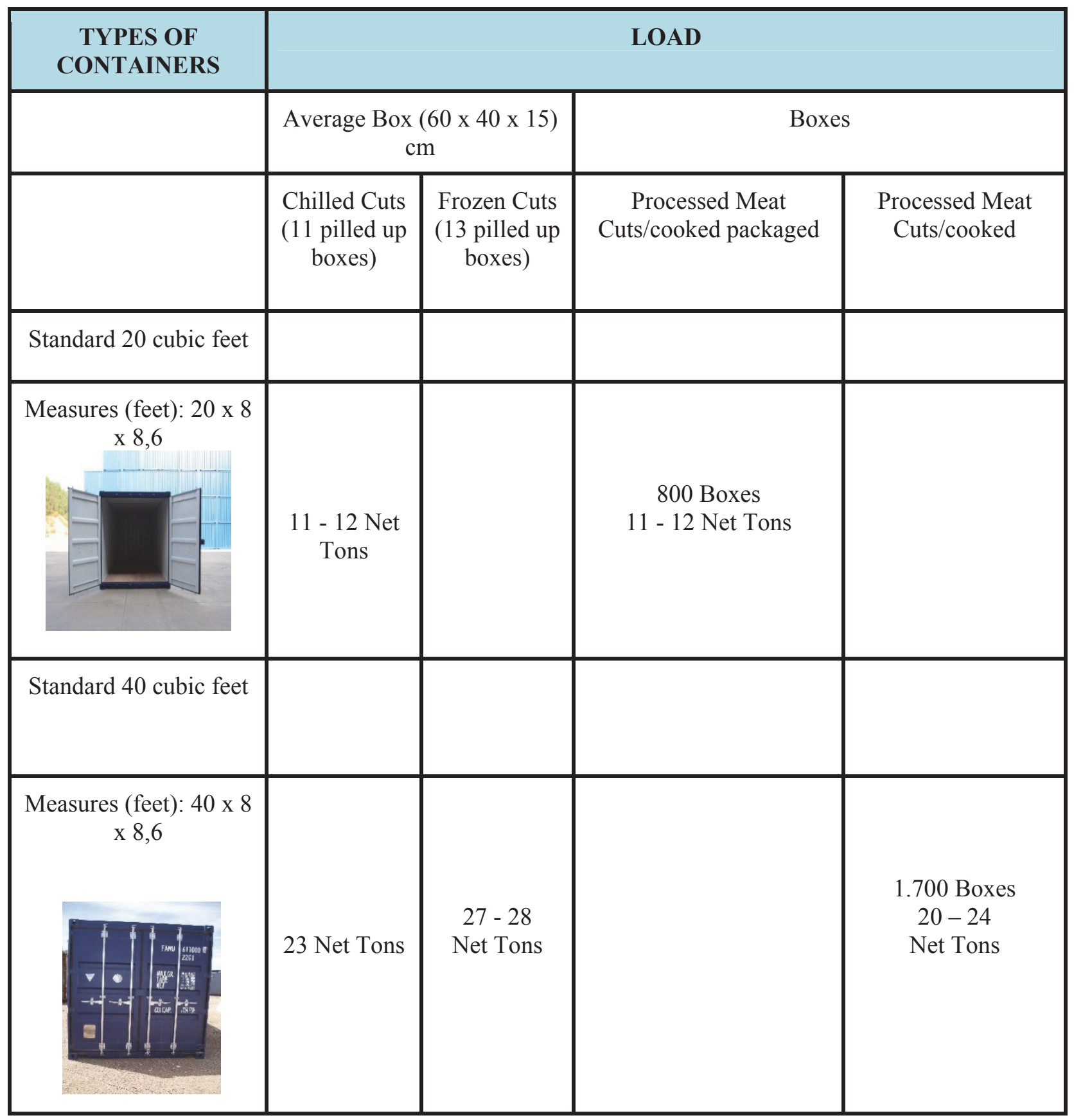

Source: IPCVA

- Customs office of origin: In the case of land-sea or intermodal air shipments, customs processes usually take place at the port/airport; however, there is also the possibility of doing it at the factory. The main Argentine port for meat exports is Buenos Aires.

- Transportation: Transportation of final products represents the single most important component of logistical costs for most companies. Meat trade practices utilizes three modes of transport: air, sea, and land. Most of the cases involves a terrestrial-maritime intermodal load. Air transport is 
the most expensive while sea transport is the cheapest and is directly related to the size of the warehouses and the average transit time.

- Country traffic in the origin (pick up): The pick-up at origin is carried out by terrestrial transport. Container chassis of 20 or 40 cubic feet are the most convenient. The net load of the containers is related to the maximum weights that are authorized by internal tolls. The limits are usually standardized globally, although there can be minimal differences which are specific to a country.

- International freight: The incidence of international freight and the risk associated with the movement of goods to their destinations is high. The magnitude of the risk is related to the nature of the merchandise, its packaging, the urgency of shipping, handling, and the availability of mode of transport. The choice of the international freight is established based on the "affinity value," that is, the adequacy of transport means in relation to the merchandise to be exported. On the other hand, "traffic value" is the set of features of one means of transport, such as speed, load capacity, load safety, the comfortability, and economic value.

The "affinity value" and "traffic value" in the international trade of meat products indicate that transport is dominated by the maritime modality and then by the air. Sometimes the routes define the mode of transport since the hygienic or legal restrictions of the destinations throw away some possibilities. Although the buyer selects the mode of transport because the clause of sale is FOB or FOT, in the so-called green markets the organic meat products from the outside come in via the sea; this is due to the emission of carbon dioxide from airplanes.

- Country traffic in place of destination (delivery): Land is the mode of transport that is commonly used. Some importers sell their products to closed containers, and others use a distribution system of their own or outsourced by the transporters.

- Documentation: In the presence of an established business relationship, the documentation is sent by courier, and in case the customer requires it to process licenses or certifications, it is forwarded via electronic mail or fax.

- Customs office of destination: Shipments of merchandise carry customs and sanitary controls in the port where they land. In very few cases, deposits are used for shipments of meat cuts.

- Marketing: This type of operation presents different "doors" in destination, namely: the refrigerator, the chain of supermarkets, hotels, or restaurants. Entering the different markets means adapting the supply to the physical and sanitary requirements, which requires implementing complete market research.

\section{CONCLUSIONS}

This paper has highlighted the importance of logistics in the optimization of the value chain and its impact on the final product for exportation. The individual behavior of each of the links does not contribute to optimization of the process as a whole, but it is necessary to achieve synergy between the various links. This has made it possible to understand the importance of animal welfare practices in the final product in regard to quality and quantity; it has also enabled us to get a perspective of the economic damages caused by failure to comply with AW practices.

As a conclusion, it is important to note the following: a) human beings play a vital role in the RVG system because they must intervene, control and manage the entire environmental supply and relevant resources in a rational way. This is not only for their specific benefit but also that of the plants, animals, soil, ecosystem and biotic community that constitute it. It is important to point out that it is only in RVG that an integral and holistic management process is implemented which involves the soil, animals, plants, and man. This integral management process generates a virtuous circle, in which the players involved receive a dignified, respectful, responsible, and harmonious handling which is specific to their needs. There is no other approach of contemporary livestock rearing which operates in this manner. b) Logistics is a continuous and interlinked chain and understanding it in its entirety improves the quality of management for both exporters and importers. It is thus essential to understand comprehensively the meat 
export logistics chain and the activities of each player. c) The advantages of re-boosting the value added to export beef through the RVG will be positively felt throughout the value chain in the following ways: (i) The livestock will have stable and sustainable demand without periodic oscillations; (ii) The industry will register increased employment opportunities and obtain a significant price differential for marketing of organic products; (iii) At the national level there will be increased foreign exchange due to the regained competitiveness and huge presence of the products in traditional markets as well as penetration into new ones. (d) It is vital to implement AW not only in production but also during transportation of the livestock from the establishment to the slaughterhouse. While at the slaughterhouse, it is equally important to avoid losses by implementing hygienic and AW practices. As discussed earlier in this paper, the economic value of such losses is equivalent to feeding approximately half a million individuals. The benefits of AW are not only as a result of an incremental cost in facilities and personal training but more importantly, a cultural change in the treatment of animals. e) There is a need to combine efforts of the private, academic and governmental sectors so as to encourage the adoption of AW and traceability along the logistics chain. This will also lead to adoption of new livestock management techniques and foster interdisciplinary research efforts.

\section{ENDNOTES}

1. Argentine Health Cattle National Service

2. Schwartz, J.D. "Cows Save the Planet," 2013

3. World Organisation for Animal Health.

4. Farm Animal Welfare Education Centre.

5. Warriss, P. "Animal Welfare. The handling animals before slaughter and the consequences for welfare and product quality",1992

6. Promotion Argentine Cattel Meat Institute. 


\section{REFERENCES}

Castro, N. (2013). Exportación de carne orgánica argentina a países verdes." Un análisis de la influencia del proceso logístico de exportación en el producto final. Bahía Blanca, Buenos Aires, Argentina.

Cultura empresarial ganadera Internacional. (2017, June 20). Cátedra del Pastoreo según Vosin. www.cegsocial.org

Dichiara, R.O., Viceconte, M.A., \& Castro, N. (2015). Sustainability in the logistics chain of the foreign trade at the example Argentina's beef export. Polonia. Uniwersytet Szczecinski, Zesxyty naukiwe $\mathrm{N}^{\circ} 869$, Problemy Transportu I Logystiki Nº 29, ISSN 1640-6818, ISSN 1644-275X.

Fried, A. E. (2009). Exportaciones de carnes vacunas de valor agregado: estrategias de diferenciación para su comercialización y negocios internacionales. Programa de inserción agrícola. Buenos Aires, Argentina.

Instituto de Promoción de la Carne Vacuna Argentina (IPCVA). (2005) Lineamientos para la formulación de escenarios del mercado de carne vacuna en la Argentina. Buenos Aires, Argentina. Programa de Estudios de Economía Aplicada. Documento de trabajo $N^{\circ} 1$.

IPCVA Instituto de Promoción de la Carne Vacuna Argentina. (2017, June 22). www.ipcva.com.ar

Millán, P. (2007). Programa de Estudio de Economía Aplicada. Estudio Sobre Logística y Costos de Exportación en el Comercio Internacional de Carne Vacuna. Análisis Comparativo con Países Competidores. Buenos Aires, Argentina.

Molinari, C.A.J. (2006). Marketing agropecuario. Buenos Aires, Argentina. Thomson Learning.

Pinheiro Machado, L.C. (2004) Pastoreo racional voisin: Tecnología. Agroecológica para el tercer milenio. Buenos Aires, Argentina. Edición: $1^{\circ}$ Hemisferio Sur.

SENASA. (2017, July 5). www.senasa.gov.ar

Thogersen, J. (2010). Country differences in sustainable consumption: the case of organic food. Journal of Macromarketing. 